\title{
Opposing Effects of Excitatory Amino Acids on Chick Embryo Spinal Cord Motoneurons: Excitotoxic Degeneration or Prevention of Programmed Cell Death
}

\author{
Jerònia Lladó, ${ }^{1}$ Jordi Calderó, ${ }^{1}$ Joan Ribera, ${ }^{1}$ Olga Tarabal, ${ }^{1}$ Ronald W. Oppenheim, ${ }^{2}$ and Josep E. Esquerda ${ }^{1}$ \\ 1 Unitat de Neurobiologia Cel/lular, Departament de Ciències Mèdiques Bàsiques, Facultat de Medicina, Universitat de \\ Lleida, E25198 Lleida, Catalonia, Spain, and 2Department of Neurobiology and Anatomy and Neuroscience Program, \\ Wake Forest University School of Medicine, Winston-Salem, North Carolina 27157
}

Acute administration of a single dose of NMDA on embryonic day (E) 7 or later induces a marked excitotoxic injury in the chick spinal cord, including massive necrotic motoneuron (MN) death. When the same treatment was performed before E7, little, if any, excitotoxic response was observed. Chronic treatment with NMDA starting on E5 prevents the excitotoxic response produced by a later "acute" administration of NMDA. Additionally, chronic NMDA treatment also prevents the later excitotoxic injury induced by non-NMDA glutamate receptor agonists, such as kainate or AMPA. Chronic NMDA treatment also reduces normal $\mathrm{MN}$ death when treatment is maintained during the period of naturally occurring programmed cell death (PCD) of MNs and rescues MNs from PCD induced by early peripheral target deprivation. The trophic action of chronic NMDA treatment appears to involve a downregulation of gluta- mate receptors as shown by both a reduction in the obligatory NR1 subunit protein of the NMDA receptor and a decrease in the kainate-induced $\mathrm{Co}^{2+}$ uptake in MNs. Both tolerance to excitotoxicity and trophic effects of chronic NMDA treatment are prevented by the NMDA receptor antagonist MK-801. Additionally, administration of MK-801 alone results in an increase in MN PCD. These data indicate for the first time that early activation of NMDA receptors in developing avian $\mathrm{MNs}$ in vivo has a trophic, survival-promoting effect, inhibiting PCD by a target-independent mechanism that involves NMDA receptor downregulation.

Key words: excitatory amino acids; NMDA; motoneurons; programmed cell death; chick embryo; spinal cord; excitotoxicity; glutamate-induced neuroprotection
During the last two decades, programmed cell death (PCD) has been extensively recognized as a key feature of normal development of the nervous system. The pioneering studies of Viktor Hamburger and Rita Levi-Montalcini in the chick embryo have been substantiated by more recent studies showing that elimination of neuronal cells by PCD is essential for the correct assembly of the nervous system (for review, see Oppenheim, 1991). Lumbar spinal cord motoneurons (MNs) in the chick embryo undergo PCD mainly in a well defined period extending from embryonic day (E) 6 to E12 (Hamburger, 1975; Chu-Wang and Oppenheim, 1978), leading to a $50 \%$ reduction of the initially differentiated $\mathrm{MN}$ pool. Neurotrophic factors and neuromuscular activity regulate the extent of the MN PCD (Pittman and Oppenheim, 1978; deLapeyrière and Henderson, 1997). Excitatory amino acids, endogenously released by spinal cord interneurons, are involved in the generation of motor activity during development (Barry and O'Donovan, 1987). Although it is well established that glu-

Received July 30, 1999; revised Sept. 9, 1999; accepted Sept. 15, 1999.

This work was supported by Ministerio de Educación y Ciencia Grant SAF970083, grants from the Fundació La Marató de TV3 and Ajuntament de Lleida, and National Institutes of Health Grant NS 20402 (R.W.O.). We thank Ester Vàzquez and Anna Naco for their technical assistance, and Osvaldo Delbono, Irene M. Soler, and Anna Petit for their contributions in some experiments of this work.

Correspondence should be addressed to Josep E. Esquerda, Unitat de Neurobiologia Cel·lular, Departament de Ciències Mèdiques Bàsiques, Facultat de Medicina, Universitat de Lleida, Av. Rovira Roure 44, E25198 Lleida, Catalonia, Spain. E-mail: josep.esquerda@cmb.udl.es.

Copyright (C) 1999 Society for Neuroscience 0270-6474/99/1910803-11\$05.00/0 tamate receptors are important for synaptic differentiation and plasticity, the role of glutamate receptors in the regulation of normally occurring MN PCD has not been determined. In cultured neurons, glutamate may be either trophic or toxic for neurons according to the modulation of intracellular calcium levels (Choi, 1987; Balázs et al., 1988); moreover, glutamate can also modulate neurotrophic factors (Barger and Mattson, 1995).

Because glutamate neurotoxicity may be involved in the pathogenesis of MN diseases, it is important to obtain information about how glutamate can regulate the life or death of MNs during normal development. In the present study, we analyze the effects of the pharmacological alteration of glutamate receptors on $\mathrm{MN}$ survival in the chick embryo. Previously, we have seen that the vulnerability of the chick embryo MNs to damage by acute exposure to excitatory amino acid agonists develops rather abruptly between E6 and E7 (Calderó et al., 1997). After this time, application of a single dose of NMDA or other excitotoxins produces a conspicuous excitotoxic spinal cord injury, including a massive necrotic MN death. Here, we show that chronic treatment with NMDA starting on E5 prevents the development of this type of excitotoxic response. In addition, this treatment has a trophic, survival-promoting effect by reducing normally occurring PCD of MNs via a target-independent mechanism that involves NMDA receptor downregulation. Accordingly, there was an increase in normally occurring PCD after blockade of endogenous NMDA receptor activity.

Parts of this paper have been published previously in abstract form (Calderó et al., 1998a). 


\section{MATERIALS AND METHODS}

Pharmacological experiments. Experiments were done with fertilized chicken eggs purchased from COPAGA (Lleida, Catalonia, Spain) and incubated in the laboratory. Stage of embryos was determined according to the Hamburger and Hamilton (1951) stage series. On E5, a small window was made in the shell to expose the chorioallantoic membrane. In one group of embryos, hindlimb buds were unilaterally removed on E2 (stage 16), as described previously (Calderó et al., 1998b).

NMDA, kainic acid, and AMPA were from Sigma (St. Louis, MO). Dizocilpine maleate (MK-801) was from Research Biochemicals (Natick, MA). CNQX was from Tocris Cookson (Bristol, UK). Drugs were dissolved in saline. In ovo treatments were performed by applying the drugs directly onto the chorioallantoic membrane in volumes of $50-150 \mu \mathrm{l}$.

Histology and cell counts. Embryos were fixed in Carnoy's solution and processed for paraffin embedding. Serial transverse sections of 6-12 $\mu \mathrm{m}$ obtained through the entire lumbosacral segment of the spinal cord were stained with thionin or hematoxylin and eosin. Apparently healthy MNs and pyknotic cells present in the lumbar lateral motor column (LMC) were counted in every 20th and 10th section, respectively, according to previously established criteria (Clarke and Oppenheim, 1995; Calderó et al., 1997).

Immunocytochemistry. Whole chick embryos or dissected spinal cords were fixed with cold $4 \%$ paraformaldehyde in $0.1 \mathrm{M}$ phosphate buffer, $\mathrm{pH}$ 7.4. Frozen sections were processed for immunocytochemistry by using the standard avidin-biotin peroxidase procedure using a mouse monoclonal antibody against NMDAR1 (PharMingen, San Diego, CA) diluted 1:500.

Motility recordings. Motility recordings were done under a binocular microscope in a group of embryos that were later histologically studied. Embryonic motility was counted, in periods of $3 \mathrm{~min}, 60 \mathrm{~min}$ after either saline or NMDA administration. The number of active movements of any part of the embryo was recorded on E5 and E6, but after the initiation of limb activity on E6, only movements of the right leg were counted in older embryos (E7-E13).

Cobalt uptake. The $\mathrm{Co}^{2+}$ uptake method was performed following a modified protocol described by Pruss et al. (1991). Spinal cords from E10 and E16 chick embryos, treated with either saline or NMDA, were rapidly dissected and placed in ice-cold uptake buffer containing (in $\mathrm{mM}$ ): 139 sucrose, $57.5 \mathrm{NaCl}, 5 \mathrm{KCl}, 2 \mathrm{MgCl}_{2}, 2 \mathrm{CaCl}_{2}, 12$ glucose, and 10 HEPES, pH 7.6. Once dissection was completed, either whole (for E10 embryos) or hemisected (for E16 embryos) spinal cords were placed in a tissue slice chamber (Fine Science Tools, Heidelberg, Germany) and continuously perfused with oxygenated uptake buffer at $27^{\circ} \mathrm{C}$ for $45 \mathrm{~min}$. Samples were then stimulated for 15 min with $100 \mu \mathrm{M}$ kainate, or $100 \mu \mathrm{M}$ NMDA dissolved in uptake buffer containing $5 \mathrm{mM} \mathrm{CoCl}$. After washing in $\mathrm{Ca}^{2+}$ and $\mathrm{Mg}^{2+}$ free uptake buffer containing 2 mM EDTA to remove the nonspecifically bound $\mathrm{Co}^{2+}, \mathrm{Co}^{2+}$ was immobilized by incubating the samples with $\mathrm{Ca}^{2+}$ and $\mathrm{Mg}^{2+}$ free uptake buffer containing $2 \mathrm{mM}$ EDTA and $0.75 \%\left(\mathrm{NH}_{4}\right)_{2} \mathrm{~S}$ for $5 \mathrm{~min}$. Samples were washed with uptake buffer, fixed in Carnoy's solution overnight, dehydrated, embedded in paraffin, and serially sectioned. CoS precipitate was amplified by a silver developer containing $0.12 \% \mathrm{AgNO}_{3}, 0.4 \%$ sodium acetate, $0.04 \%$ Triton $\mathrm{X}-100,7.5 \%$ acetic acid (eight parts), $5 \%$ sodium tungstate (one part), and $0.25 \%$ ascorbic acid (one part) in $\mathrm{H}_{2} \mathrm{O}$. (Allcorn et al., 1996). Sections were lightly counterstained with thionin, dehydrated, and coverslipped with DPX mountant for microscopy. The percentage of labeled area in the lumbar LMC representing $\mathrm{Co}^{2+}$ uptake of MNs was measured in every 10th section using PC-image 2.2 (Newcastle Technopole, Newcastle upon Tyne, UK). Five to seven sections were analyzed in each spinal cord. To explore whether or not NMDA receptors in spinal cord were permeable to $\mathrm{Co}^{2+}$, some samples were incubated in a free $\mathrm{Mg}^{2+}$ uptake buffer containing $100 \mu \mathrm{M}$ NMDA and $10 \mu \mathrm{M}$ glycine. In these conditions, neurons were not stained by $\mathrm{Co}^{2+}$ (data not shown), as shown previously for cerebellar slices (Pruss et al., 1991).

Western blot analysis. For each experiment, 20-30 spinal cords from embryos treated with either saline or NMDA (E5-E9) were dissected in

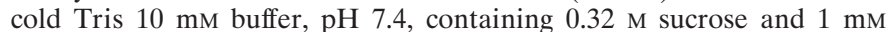
$\mathrm{MgCl}_{2}$, and pooled for homogenization. The homogenate was centrifuged at $1000 \times g$, and the supernatant was used to obtain a crude membrane fraction by centrifugation at $100,000 \times g$. The membrane pellet was resuspended in $10 \mathrm{mM}$ HEPES-KOH buffer, $\mathrm{pH}$ 7.4, containing $140 \mathrm{~mm} \mathrm{KCl}$ and $20 \mathrm{~mm} \mathrm{NaCl}$. All media used contained a protease inhibitor cocktail (1 mM PMSF, $1 \mu \mathrm{M}$ pepstatin $100 \mu \mathrm{M} \mathrm{L}-1-p$-tosylamino2-phenyl chloromethyl ketone, $25 \mu \mathrm{g} / \mathrm{ml}$ chymostatin, leupeptin, and antipain, 1 mm EGTA, 1 mm EDTA, and 5 mM DTT). Protein concen- tration was determined by using DC Protein Assay (Bio-Rad, Hercules, CA). Twenty-five micrograms of protein from each sample were loaded on SDS-PAGE and later transferred to nitrocellulose membranes for Western blotting by using a monoclonal antibody against NMDAR1 (PharMingen, San Diego, CA) diluted 1:200. Signal was detected using appropriate secondary antibodies and the ECL detection system as recommended by the manufacturer (Amersham, Buckinghamshire, UK) and evaluated by means of a Lumi-Imager (Boehringer Mannheim, Mannheim, Germany). Results were obtained from three separate experiments.

\section{RESULTS \\ Exposure to excitatory amino acid agonists induces acute spinal cord damage and massive excitotoxic (necrotic) MN death}

Treatment of embryos at different embryonic ages (later than E7) with a single dose $(0.1 \mathrm{mg}$ or higher) of NMDA resulted in a dramatic lesion of spinal cord affecting the entire gray matter. Vulnerability was developmentally regulated in that younger embryos (earlier than E7) were more or less completely resistant to excitotoxicity. On E7, lesions started to be extensive, becoming even more massive on E10 and later (Fig. 1A,B). Histopathological changes consisted of a severe interstitial edema, cellular swelling, and chromatin condensation that led to a massive and acute cytolysis, a dramatic neuronal depletion, and later gliosis; lumbar LMC MNs were almost completely depleted (Tables 1, 2). Ultrastructural morphology and in situ demonstration of DNA fragmentation of dying MNs indicated a necrotic, rather than apoptotic, mode of degeneration (Ciutat et al., 1996). Similar or even more extensive damage was obtained after treatment with either kainic acid or AMPA (0.1-0.5 mg) (Fig. 1C, Table 2). Dorsal root ganglia were in all the cases not affected by any of the treatments. NMDA and kainate-AMPA toxicity was abolished by pretreatment with MK-801 (0.2 mg) and CNQX (0.5 mg), respectively.

\section{Chronic treatment with NMDA induces tolerance against acute exposure to NMDA and non-NMDA glutamate receptor agonists}

We have examined the influence of early (when vulnerability to NMDA excitotoxicity is not yet acquired) pharmacological activation of NMDA receptors on the later appearance of sensitivity to excitotoxin-induced damage. In one group of embryos, a single dose of $0.25 \mathrm{mg}$ of NMDA was administered on E10. Results were compared with another group of embryos treated daily with the same dose of NMDA from E5 to E9. As expected, the application of $0.25 \mathrm{mg}$ of NMDA on E10 resulted in severe damage of the spinal cord with a dramatic depletion of MNs $12 \mathrm{hr}$ later. Conversely, the same dose applied to embryos pretreated with NMDA from E5 (Table 2) did not induce a decrease in MN numbers, and spinal cord histopathology was apparently normal (Fig. $1 B, B^{\prime}$ ). Chronic treatment with NMDA was also effective in preventing acute toxicity induced by non-NMDA receptor-acting excitotoxins, as evidenced after application of kainate $(0.5 \mathrm{mg})$ or AMPA (0.1 mg) on E10 embryos (Fig. $1 C, C^{\prime}$, Table 2). In the same way, chronic treatment (E5-E9) with kainate $(0.2 \mathrm{mg})$ offered protection against a pulse of kainate $(0.2 \mathrm{mg})$, AMPA $(0.1$ $\mathrm{mg})$, or NMDA $(0.1 \mathrm{mg})$, given on E9 or E10; these pulses elicited only minimal abnormalities in the same conditions (acute) that would otherwise lead to massive spinal cord damage in control embryos.

A single injection of NMDA on E15 produced a massive $\mathrm{MN}$ loss $(99 \%)$, whereas a sustained NMDA treatment (E5-15) resulted in only a $48 \%$ loss of MNs. This kind of tolerance required 

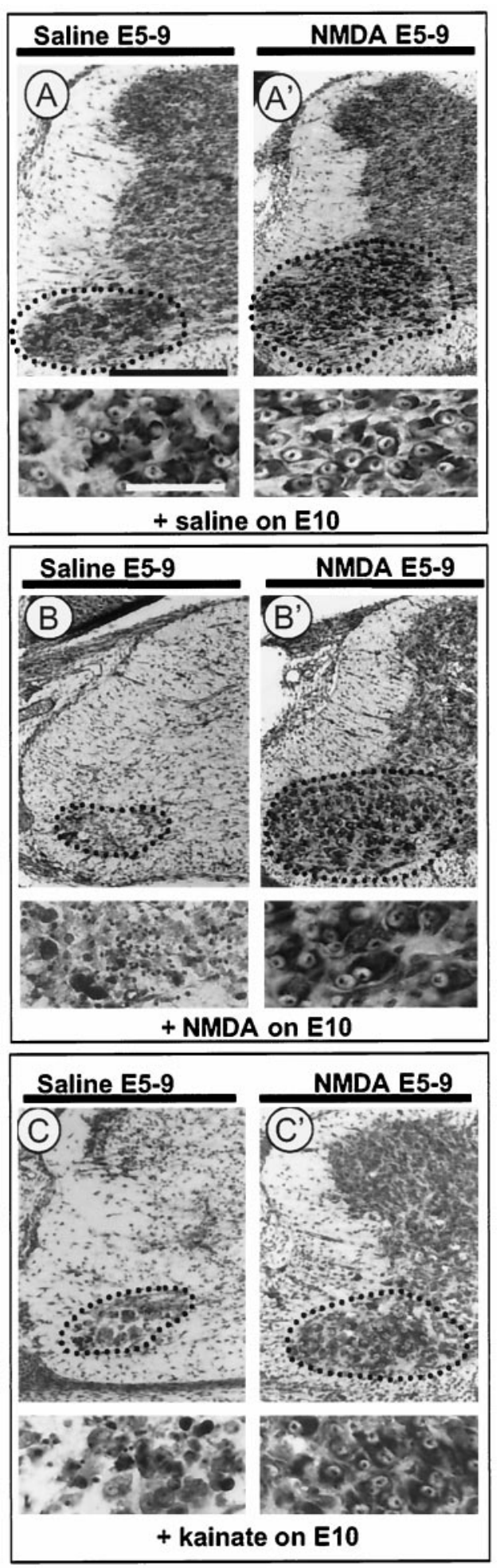

Figure 1. Nissl-stained sections from E10 chick embryo lumbar spinal cords after different regimens of treatment. Top rows, Low-magnification views of a hemisection of a spinal cord, with the LMC indicated in dots. Bottom rows, High magnification of the corresponding LMC. $A, B$, and $C$ were treated with saline from $\mathrm{E} 5$ to $\mathrm{E} 9$, whereas $A^{\prime}, B^{\prime}$, and $C^{\prime}$ received the standard trophic NMDA treatment. At the end of the treatment, embryos received a pulse of saline $\left(A, A^{\prime}\right), 0.25 \mathrm{mg}$ NMDA $\left(B, B^{\prime}\right)$, or 0.5 mg kainate $\left(C, C^{\prime}\right)$ on E10 and were killed $12 \mathrm{hr}$ later. Note that NMDA trophic treatment results in an enlargement of the LMC and protects against acute damage induced by pulses of excitotoxins. Scale bar (in $A$ ): top rows, $200 \mu \mathrm{m}$; bottom rows, $50 \mu \mathrm{m}$.
Table 1. Chronic NMDA treatment starting on E5 suppresses spontaneous PCD, whereas acute NMDA administration is highly toxic for MNs

\begin{tabular}{llll}
$\begin{array}{l}\text { Regimen of } \\
\text { treatment }^{a}\end{array}$ & $\begin{array}{l}\text { Motoneuron } \\
\text { numbers }(n)^{c}\end{array}$ & $\begin{array}{l}\text { \% of change } \\
\text { in motoneuron } \\
\text { numbers }\end{array}$ & $\begin{array}{l}\text { Age of } \\
\text { sampling }\end{array}$ \\
\hline Saline (E5-E8) & $14282 \pm 712(7)$ & - & E9 \\
NMDA (E5-E6) & $13384 \pm 428(5)$ & -6 & E9 \\
NMDA (E5-E8) & $18017 \pm 913(6)^{*}$ & +26 & E9 \\
NMDA (E6-E8) & $14892 \pm 854(5)$ & +4 & E9 \\
NMDA (E8) & $1064 \pm 272(5)^{* *}$ & -93 & E9 \\
Saline (E5-E9) & $12754 \pm 323(7)$ & - & E10 \\
NMDA (E5-E9) & $16763 \pm 900(6)^{* *}$ & +31 & E10 \\
MK801 + NMDA & & & \\
$\quad($ E5-E9) & $11037 \pm 753(6)$ & -13 & E10
\end{tabular}

${ }^{a} \mathrm{~A}$ daily dose of either saline or NMDA was administered at the embryonic ages indicated in parentheses. The doses of NMDA were $0.5 \mathrm{mg}$ on E5 and E6, and 0.25 mg daily on E7, E8, and E9.

${ }^{b} \mathrm{MK}-801(50 \mu \mathrm{g})$ was administered $30 \mathrm{~min}$ before NMDA.

${ }^{c}$ Number of MNs (mean \pm SEM) in the lumbar LMC. Sample size in parentheses. ${ }^{*} p<0.01$ versus saline; ${ }^{* *} p<0.001$ versus saline (Student's $t$ test).

the continuous administration of NMDA. When chronic NMDA treatment was stopped on E9 and an excitotoxic pulse was performed on E15, a massive acute MN degeneration, similar to that observed in control embryos, was detected. The same results were obtained when the excitotoxic pulse was administered on E11 and cell counts were performed on E12 (Table 2).

\section{Chronic NMDA treatment inhibits naturally occurring PCD of MNs}

When chronic NMDA treatment was started on E5 (0.5 mg on E5 and E6, and $0.25 \mathrm{mg}$ on E7, E8, and E9, our standard trophic NMDA treatment), MNs were rescued from normal PCD. The number of apparently healthy MNs present in the lumbar LMC at the end of the main period of naturally occurring $\mathrm{MN}$ death (E6-E10) was significantly higher in NMDA-treated embryos (Figs. $1 A, A^{\prime}, 2 A$; Table 1 ), and the number of pyknotic profiles was significantly reduced (Fig. $2 B$ ). This trophic effect was prevented when MK-801 (50 $\mu \mathrm{g})$ was administered $30 \mathrm{~min}$ before each NMDA injection (Table 1). Once the NMDA treatment was stopped (on E10), there was a gradual loss of the rescued MNs between E10 and E20, which was accompanied by an increase in the number of pyknotic profiles in the LMC, peaking on E12. By E20, the number of MNs and pyknotic cells in the lumbar LMC was similar in control and NMDA-treated embryos (Fig. 2A,B). One group of embryos received a daily dose of NMDA from E5 to E15 (0.5 mg on E5 and E6, and $0.25 \mathrm{mg}$ from E7 to E15). When observed on E16, embryos treated with this regimen showed a clear reduction in the number of $\mathrm{MNs}$, indicating that treatments longer than the time window corresponding to E5-E10 were not able to keep alive MNs rescued by the trophic NMDA treatment, and indeed this regimen produced some toxic effects (Table 2).

As shown in Figure 3 in which the number of movements recorded from either saline- or NMDA-treated embryos were plotted, motility was significantly decreased in E7 and E8 embryos treated with NMDA. At E9-E10, chronically treated embryos showed phases of vigorous bursts of clonic-like activity of the legs, but overall motility levels were similar to controls. From E11 to E13 (the last day studied), a dramatic decrease in motility was observed in embryos treated with NMDA. Indeed, embryos chronically treated with NMDA from E5 to E9 and killed on E16 
Table 2. Chronic NMDA treatment induces dramatic changes in the vulnerability of spinal cord MNs to undergo excitotoxic damage

\begin{tabular}{|c|c|c|c|}
\hline Regimen of treatment ${ }^{a}$ & $\begin{array}{l}\text { Motoneuron } \\
\text { numbers }(n)^{i}\end{array}$ & $\begin{array}{l}\% \text { of change in } \\
\text { motoneuron } \\
\text { numbers }\end{array}$ & $\begin{array}{l}\text { Age of } \\
\text { sampling }\end{array}$ \\
\hline Saline (E10) & $12615 \pm 463(4)$ & - & E10.5 \\
\hline NMDA $(\text { E5-E9 + E10) })^{b}$ & $16447 \pm 1340(3)^{*, \ddagger}$ & +31 & E10.5 \\
\hline NMDA $(\mathrm{E} 10)^{c}$ & $30 \pm 17(4)^{* *}$ & -99 & E10.5 \\
\hline NMDA (E5-E9) + KA (E10) ${ }^{b}$ & $13160 \pm 1658(3)^{\dagger}$ & +4 & E10.5 \\
\hline $\mathrm{KA}(\mathrm{E} 10)^{c}$ & $960 \pm 519(3)$ & -92 & E10.5 \\
\hline NMDA (E5-E9) + AMPA (E10) ${ }^{b}$ & $15426 \pm 1861(3)^{\pi}$ & +22 & E10.5 \\
\hline $\mathrm{AMPA}(\mathrm{E} 10)^{c}$ & $2967 \pm 965(3)$ & -76 & E10.5 \\
\hline Saline (E10) & $12384 \pm 442(5)$ & - & E11 \\
\hline NMDA (E10) & $138 \pm 134(9)^{* *}$ & -99 & E11 \\
\hline Saline (E5-E11) & $11472 \pm 295(5)$ & - & E12 \\
\hline NMDA (E5-E9) & $12332 \pm 1542(5)$ & +7 & E12 \\
\hline $\mathrm{NMDA}(\mathrm{E} 5-\mathrm{E} 9+\mathrm{E} 11)^{d}$ & $492 \pm 189(5)^{* *}$ & -96 & E12 \\
\hline NMDA $(\mathrm{E} 11)^{e}$ & $64 \pm 15(5)^{* *}$ & -99 & E12 \\
\hline Saline (E5-E15) & $9092 \pm 480(5)$ & - & E16 \\
\hline NMDA (E5-E9) & $10734 \pm 729(7)$ & +18 & E16 \\
\hline NMDA $(\mathrm{E} 5-\mathrm{E} 15)^{f}$ & $4770 \pm 1428(6)^{*}$ & -48 & E16 \\
\hline NMDA $\left(\right.$ E5-E9 + E15) ${ }^{g}$ & $345 \pm 179(4)^{* *}$ & -96 & E16 \\
\hline NMDA $(\mathrm{E} 15)^{h}$ & $90 \pm 70(4)^{* *}$ & -99 & E16 \\
\hline
\end{tabular}

$\overline{{ }^{a} \mathrm{~A} \text { daily dose of either saline or NMDA was administered at the embryonic ages indicated in parentheses. Except in the }}$ indicated cases, the doses of NMDA were as follows: $0.5 \mathrm{mg}$ on E5 and E6, and $0.25 \mathrm{mg}$ daily on E7, E8, E9, and E10. The doses of the other excitotoxins were $0.5 \mathrm{mg}$ of KA and $0.1 \mathrm{mg}$ of AMPA.

${ }^{b}$ A pulse of NMDA, KA, or AMPA was applied on E10 with previous NMDA treatment from E5 to E9, at the doses indicated above (regular trophic treatment).

${ }^{c}$ A pulse of NMDA, KA, or AMPA was applied on E10 without previous NMDA treatment from E5 to E9, at the doses indicated above (regular trophic treatment).

${ }^{d}$ After regular trophic treatment, a single dose of $0.25 \mathrm{mg}$ of NMDA was applied on E11.

${ }^{e}$ Single dose of $0.25 \mathrm{mg}$ on E11.

${ }^{f} \mathrm{~A}$ dose of $0.5 \mathrm{mg}$ of NMDA on E5 and E6 and $0.25 \mathrm{mg}$ daily from E7 to E15.

${ }^{g}$ After regular trophic treatment, a single dose of $0.25 \mathrm{mg}$ of NMDA was applied on E15.

${ }^{h}$ Single dose of $0.25 \mathrm{mg}$ of NMDA on E15.

${ }^{i}$ Number of MNs (mean \pm SEM) in the lumbar LMC. Sample size in parentheses.

${ }^{*} p<0.05$ versus saline; ${ }^{* *} p<0.001$ versus saline; $\ddagger p<0.001$ versus NMDA (E10); ${ }^{\dagger} p<0.01$ versus KA; $" p<0.01$ versus AMPA (Student's $t$ test).

showed an almost complete paralysis, atrophy of muscular masses, abnormal posture, stiffness, flexion of the limbs, and marked ventroflexion of toes.

\section{Induction of MN PCD by peripheral target removal is prevented by chronic NMDA treatment}

Normally occurring PCD of peripheral neurons is greatly increased after early ablation of target tissues (Hamburger, 1958; Oppenheim et al., 1978; Calderó et al., 1998b). To elucidate whether or not trophic NMDA treatment is able to circumvent PCD in the absence of peripheral nerve-muscle interactions, the neurotrophic effects of NMDA were investigated in embryos subjected to limb bud removal (LBR) on E2. LBR resulted in a complete absence of limb musculature and an extensive MN loss when evaluated on E9. Trophic NMDA treatment (E5-E8) of LBR embryos rescued MNs from target deprivation (Fig. 4).

\section{Downregulation of glutamate receptors after chronic NMDA treatment}

To investigate whether the reduction in NMDA responsiveness to excitotoxic insult could be explained by a downregulation of NMDA receptors, we examined the levels of the obligatory NMDA receptor subunit NR1 protein in spinal cord after trophic NMDA treatment. Western blots of spinal cord membrane fractions from E10 trophic NMDA-treated embryos revealed more than a $50 \%$ reduction in NR1 protein when compared with controls. If treatment was prolonged to E15, NR1 protein downregulation was maintained. However, NR1 protein downregulation recovered $48 \mathrm{hr}$ after the cessation on E9 of NMDA treatment (Fig. 5). Immunocytochemistry on sections from normal E10 embryos showed the NR1 signal localized in LMC MNs, as well as in many interneuron cell bodies, in the form of a fine punctate pattern. After chronic NMDA treatment, a reduction in immunostaining of MN somas was seen, although this was less evident than in Western blots (data not shown).

We have attempted to use a number of methods to determine how NMDA receptor downregulation in chick embryo MNs influences NMDA-mediated intracellular calcium levels. The best way to address this question is by using fluorescent calcium indicators on isolated cultured MNs. Unfortunately, MNs isolated on E6 and cultured for 4-6 d are completely resistant to excitotoxic damage, even when treated with high NMDA concentrations (1-3 mm; data not shown). This is in contrast to the results obtained in cultures of purified embryonic rat MNs in which NMDA-induced neurotoxicity was recently shown in only a restricted subset of MNs (Fryer et al., 1999). We also attempted to assay calcium levels in acutely isolated neurons from E10 spinal 

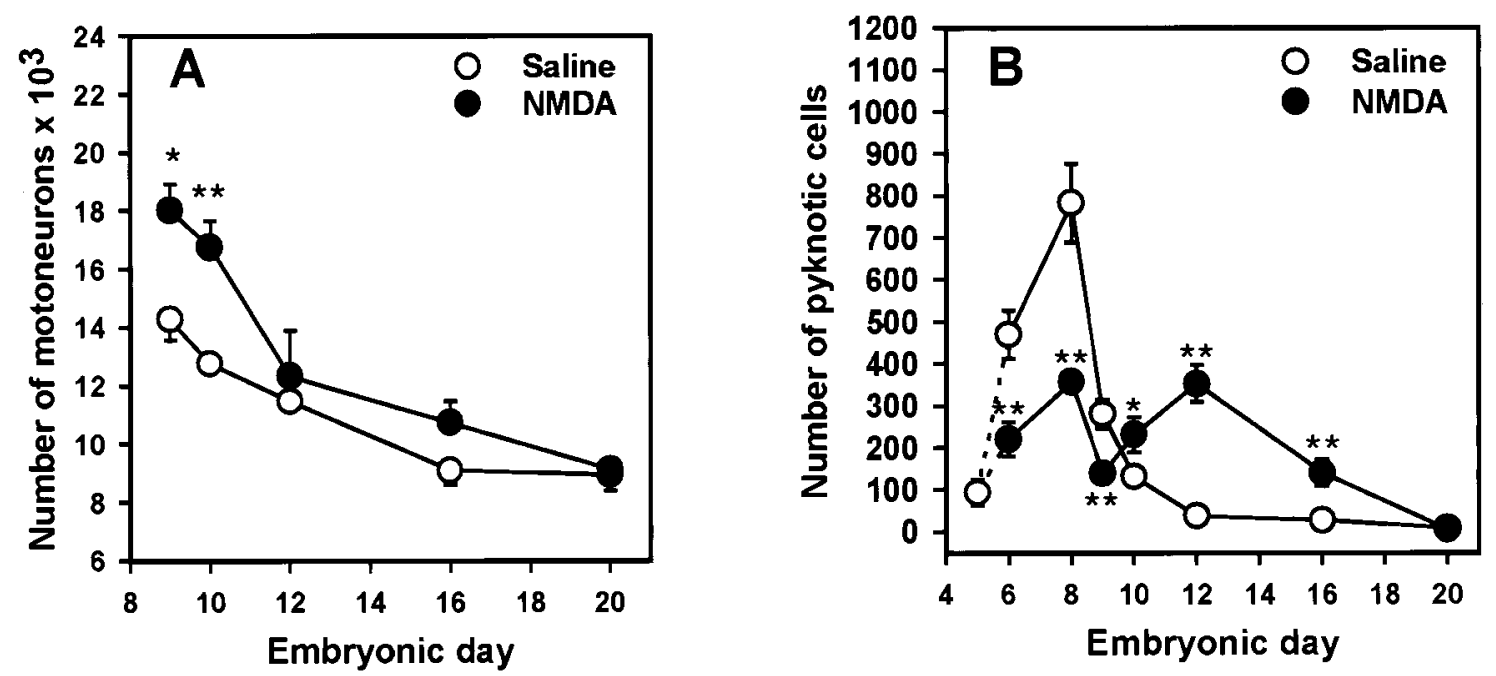

Figure 2. Number of surviving MNs $(A)$ and pyknotic cells $(B)$ in the lumbar LMC in saline (control) or trophic NMDA-treated embryos. $A$, Note that the excessive number of rescued MNs present on E9-E10 after trophic NMDA treatment is progressively lost in the subsequent developmental period. $B$, The peak of pyknotic profiles normally present on E8 in control embryos is significantly reduced by trophic NMDA treatment. Subsequently, there is an increase in the number of pyknotic cells in NMDA-treated embryos coincident with the loss of NMDA-rescued MNs. Each point represents the mean \pm SEM of four to eight embryos. Error bars are sometimes smaller than symbols. ${ }^{*} p<0.05,{ }^{* *} p<0.01$ versus saline (Student's $t$ test).

cords. However, after loading with calcium indicators, cultured neurons did not respond at all to NMDA. Most likely, proteolytic agents used during the dissociation procedures altered cell surface NMDA receptors. Thus, it appeared that the only means to address this issue was to use an intact spinal cord preparation. Taking advantage of the fact that chronic NMDA treatment induces cross-tolerance against kainate excitotoxicity, we examined whether or not tolerance was correlated with a decrease in the $\mathrm{Co}^{2+}$ uptake induced by kainate stimulation. This technique can be performed in isolated intact nerve tissue and reflects calcium entry through AMPA-kainate calcium-permeable receptors (Pruss et al., 1991; Allcorn et al., 1996; Caicedo et al., 1998). After spinal cord stimulation for 15 min with $100 \mu \mathrm{m}$ kainate in an oxygenated physiological medium containing $\mathrm{Co}^{2+}$, trapped $\mathrm{Co}^{2+}$ in MNs was 4.6-fold lower in E10 embryos treated with the NMDA trophic protocol (E5-E10). $\mathrm{Co}^{2+}$ staining in control spinal cord revealed extensive and strong labeling of LMC MN somas that extended into dendritic arbors and to a less degree into the axons (Fig. 6A). Kainate stimulation of spinal cords from embryos chronically treated with NMDA showed a dramatic change in this pattern in that staining of MNs was considerably reduced (Fig. 6B). After cessation of treatment on E10, there were no significant differences in $\mathrm{Co}^{2+}$ uptake between control and NMDA-treated embryos on E16 (compare Figs. 6C,D, $7 A, B) . \mathrm{Co}^{2+}$ staining was almost completely abolished when kainate stimulation was done in the presence of $30 \mu \mathrm{M}$ CNQX (Fig. 6E,F).

\section{Blockade of endogenous NMDA receptor activity increases normally occurring PCD of MNs}

It has been reported recently that endogenous glutamate exerts a trophic role regulating neuronal PCD in developing rat brain in vivo (Ikonomidou et al., 1999). To explore whether or not the survival-promoting effects of NMDA described here mimic an effect of endogenous glutamate on MNs, the normal activity of NMDA receptors was blocked at the peak of naturally occurring
PCD by means of a pulse of MK-801 administered on E7. The resulting effects of this treatment on the number of dying MNs were analyzed $12 \mathrm{hr}$ later. As shown in Figure 8, the number of pyknotic cells in the lumbar LMC was significantly increased in a dose-dependent manner, indicating that inactivation of NMDA receptors at critical stages of embryonic development promotes the death of MNs.

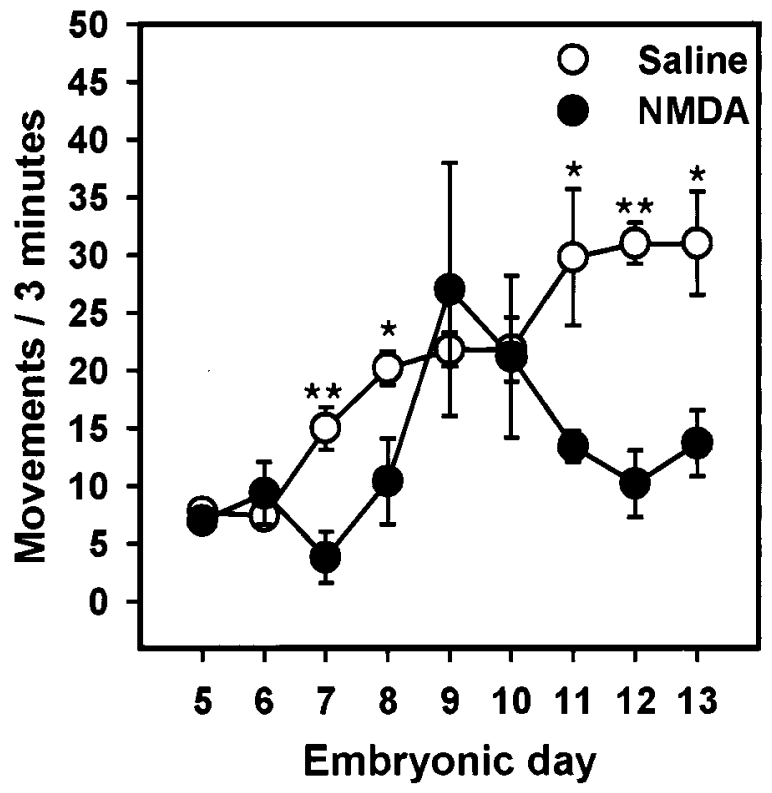

Figure 3. Effects of either saline or trophic NMDA treatment on the number of active embryonic movements. The developmental pattern of motor activity is drastically changed by trophic NMDA treatment. The high values of error bars on E9 and E10 NMDA-treated embryos are caused by large variations in movements commonly observed at these ages as a consequence of NMDA treatment. Each point represents the mean \pm SEM of four to eight embryos. Error bars are sometimes smaller than symbols. ${ }^{*} p<0.05,{ }^{*} p<0.01$ versus saline (Student's $t$ test). 

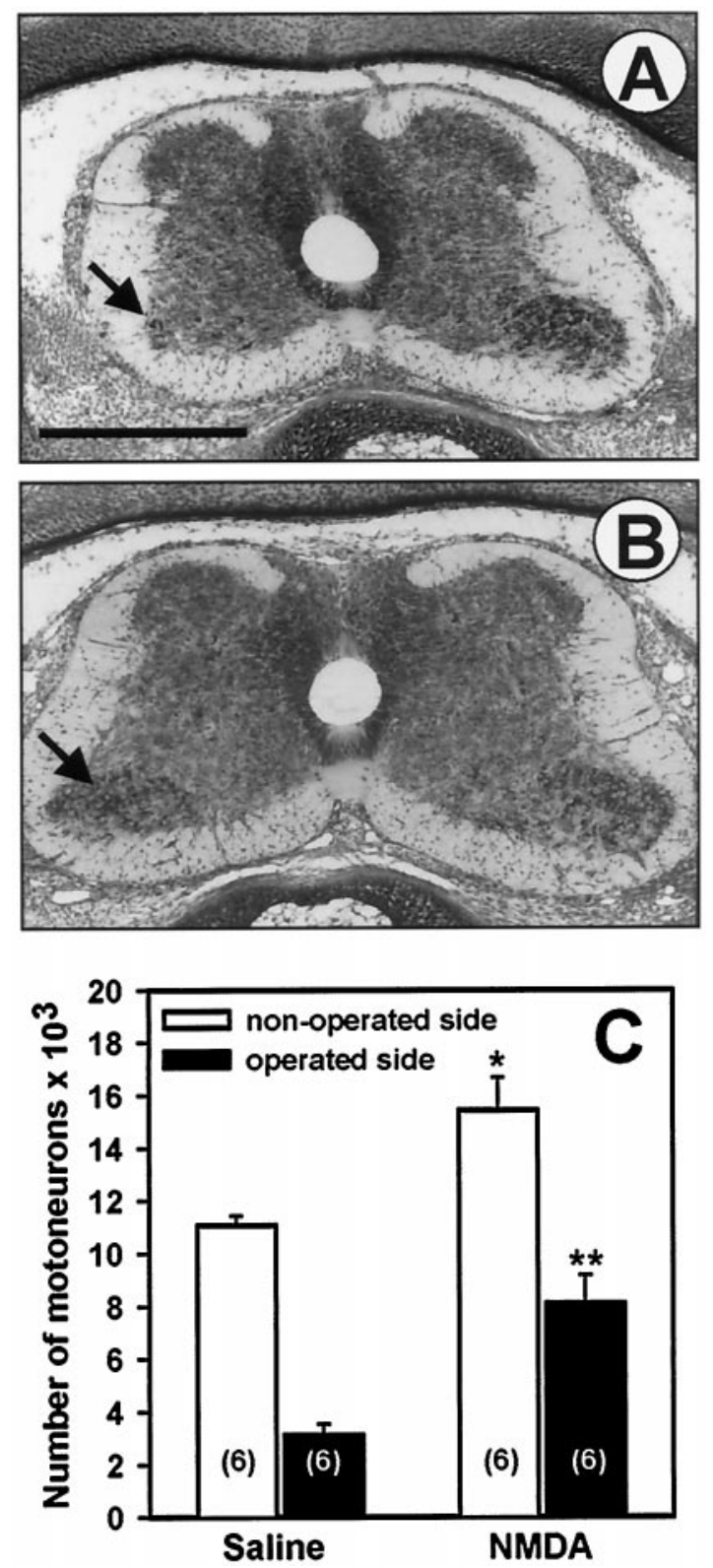

Figure 4. Effect of trophic NMDA treatment on MN survival after LBR performed on E2. $A, B$, Photomicrographs taken from E9 LBR operated embryos after treatment from E5 to E8 with either saline $(A)$ or NMDA $(B)$. Note the dramatic depletion of MNs in the LMC on the operated side of saline-treated embryos (arrow in $A$ ) and compare with the increased number of MNs in NMDA-treated embryos on the operated side (arrow in $B$ ). Scale bar (in $A$ ): $A, B, 200 \mu \mathrm{m}$. $C$, Number (mean $\pm \mathrm{SEM}$ ) of MNs in lumbar LMC of embryos from LBR experiments. ${ }^{*} p<0.01$ versus saline nonoperated; ** $p<0.01$ versus saline operated (Student's $t$ test). Numbers in parentheses indicate sample sizes.

\section{DISCUSSION}

The results of this study indicate the following: (1) acute in ovo application of either NMDA or other excitotoxins, such as kainate or AMPA, has a potent neurotoxic effect on chick embryo spinal cord MNs; (2) spinal cord vulnerability to damage by exogenous administration of excitotoxins is developmentally regulated; (3) NMDA pretreatment of embryos before the acquisition of vulnerability (i.e., earlier than E7) protects the spinal cord against the toxicity induced by a subsequent exposure to either
NMDA or non-NMDA receptor-specific excitotoxins; (4) when pretreatment starts as early as E5 (trophic NMDA treatment), a robust neurotrophic-like action, significantly reducing normally occurring MN PCD, was observed; (5) it appears that the mechanism by which NMDA prevents normal PCD of MNs does not require peripheral nerve-muscle interactions because it was possible to rescue MNs even after early target deprivation; (6) both the tolerance to an acute excitotoxic lesion and the neurotrophiclike effects are transient and cannot be maintained after E10, even if treatment is continued; (7) trophic treatment with NMDA involves a reversible downregulation of NR1 receptor protein and a decrease of the functional activity of non-NMDA glutamate receptors, as indicated by $\mathrm{Co}^{2+}$ uptake; and (8) pharmacological inactivation of NMDA receptors during the critical period of normally occurring PCD enhances $\mathrm{MN}$ death.

It has been reported that neurons in culture, including MNs, can be kept alive in the absence of neurotrophic factors when grown in depolarizing media with high $\mathrm{K}^{+}$by a mechanism involving $\mathrm{Ca}^{2+}$ entry (Nishi and Berg, 1981; Gallo et al., 1987; Koike et al., 1989; Soler et al., 1998). In cultured cerebellar granule cells, the neurotrophic action of high $\mathrm{K}^{+}$can be mimicked by NMDA (Burgoyne et al., 1993), involving the $\mathrm{Ca}^{2+}{ }_{-}$ phosphatidyl-inositol 3-kinase pathway (Zhang et al., 1998). The survival-promoting effects of high $\mathrm{K}^{+}$led to the postulation of the calcium set point hypothesis by Johnson et al. (1992), which states that a modest sustained elevation of cytoplasmic $\mathrm{Ca}^{2+}$ promotes neuronal survival in the absence of neurotrophic factor support. In contrast, high cytoplasmic $\mathrm{Ca}^{2+}$ levels are extremely toxic for neurons. Thus, the neurotrophic effects of NMDA reported here may be a consequence of the ability of the excitatory amino acid to increase intracellular $\mathrm{Ca}^{2+}$ levels sufficient to lower the dependence of MNs on neurotrophic factors for survival. Moreover,

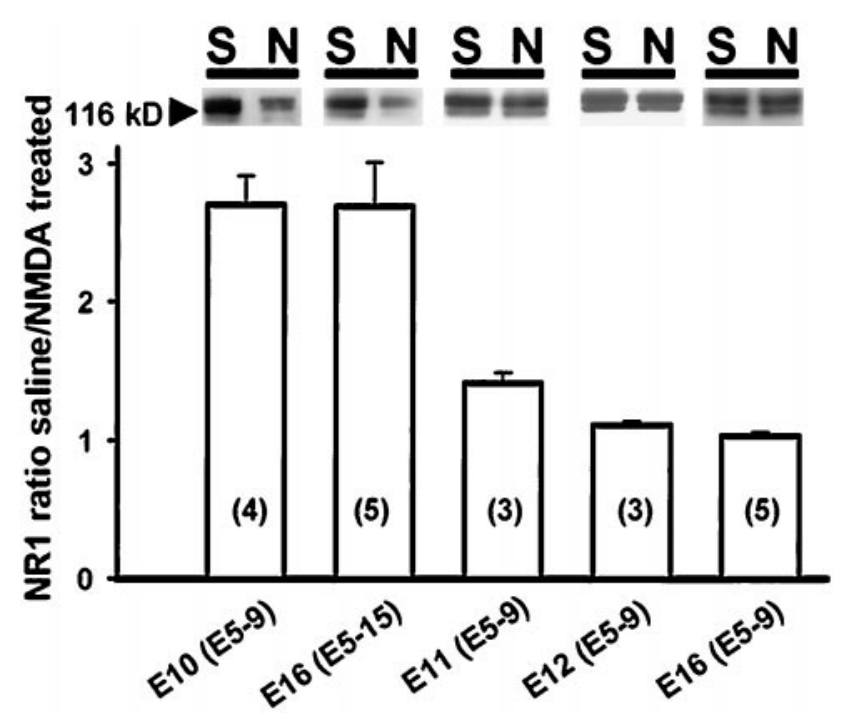

Figure 5. Identification of NR1 protein in Western blots of spinal cord membrane fractions from E10, E11, E12, and E16 embryos. $S$, Saline; $N$, after chronic NMDA treatment. The ratio (mean \pm SEM) of densitometric values from saline versus NMDA treatment is plotted for each experimental condition. Numbers in parentheses in bars indicate sample sizes; each sample represents the total membrane fraction obtained from at least 20 spinal cords. Legends in $x$-axis indicate the embryonic day of sampling and the duration of treatment (in parentheses). Note that, when NMDA treatment is stopped, the downregulation of NR1 protein is reversed. 

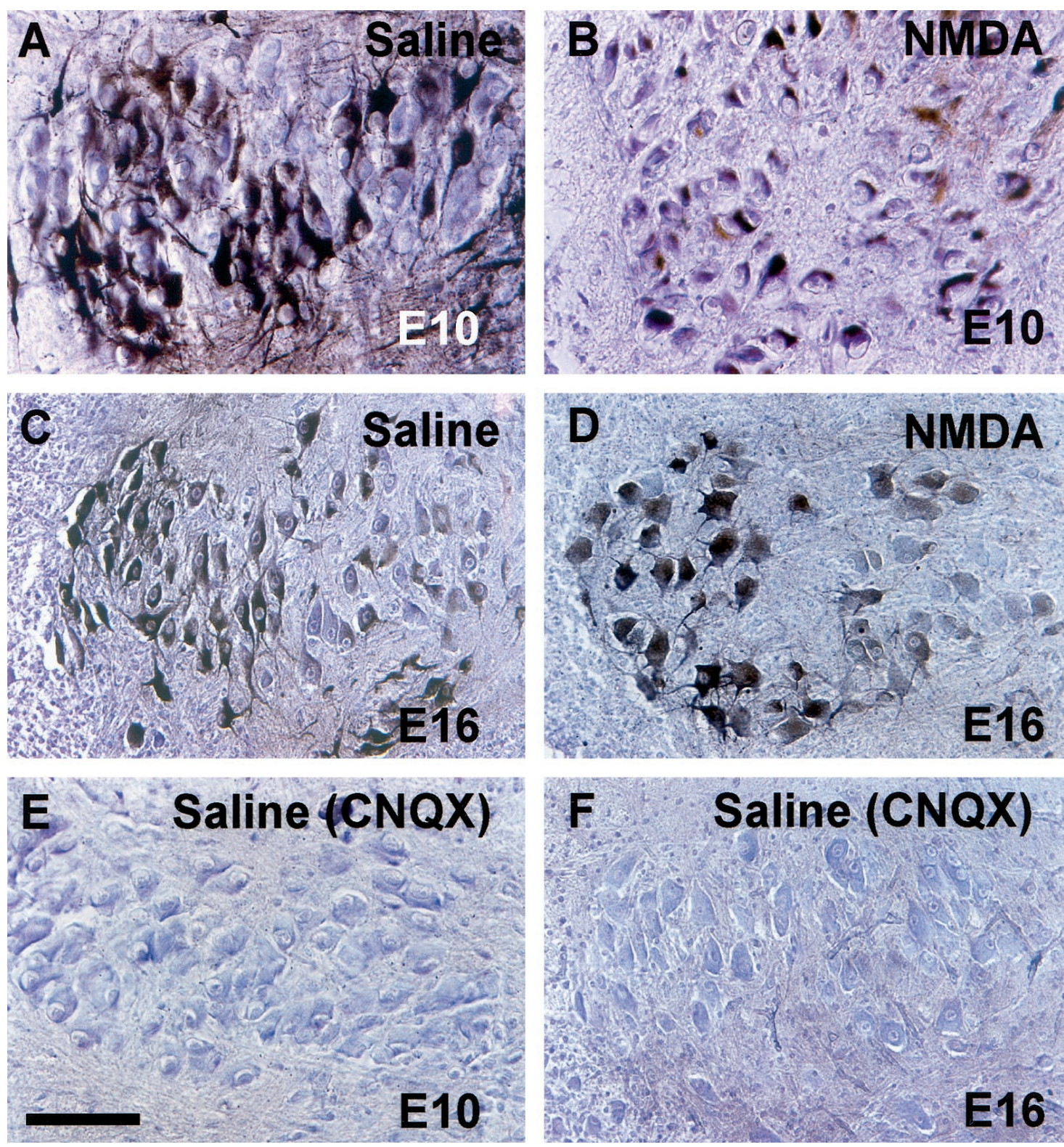

Figure 6. $\mathrm{Co}^{2+}$ uptake in lumbar LMC MNs of $\mathrm{E} 10(A, B, E)$ and $\mathrm{E} 16(C, D, F)$ chick embryos after 15 min stimulation with $100 \mu \mathrm{M}$ kainate. Embryos were treated previously from E5 to E9 with either saline $(A, C, E, F)$ or the trophic protocol of NMDA $(B, D)$. Spinal cord preparations were also stimulated in the presence of CNQX $(30 \mu \mathrm{M} ; E, F)$. Sections were counterstained with thionin. Note that the trophic treatment with NMDA greatly reduces $\mathrm{Co}^{2+}$ uptake in MNs on E10 $(A, B)$ but not on E16 $(C, D)$ embryos. Kainate stimulation in the presence of $C N_{Q X}$ abolishes Co ${ }^{2+}$ uptake $(E$, $F$ ). Scale bar (in $E$ ): $A, B, E, 50 \mu \mathrm{m} ; C, D, F, 100 \mu \mathrm{m}$.

agonist-induced $\mathrm{Ca}^{2+}$ entry would not be sufficient to elicit an excitotoxic response in this situation because, as we have shown here, NMDA receptors are downregulated. This may also explain why, in embryos pretreated with NMDA from E5, a later excitotoxic pulse is unable to trigger acute neuronal death.

Our data show that trophic NMDA treatment results in a more than $50 \%$ reduction in the obligatory NR1 subunit, which can be reversed by cessation of the NMDA treatment. Additionally, we observe a correlation between levels of NR1 protein and the susceptibility for sustaining NMDA-induced damage. Other studies have shown that the activity of the NMDA receptor plays a key role in its own regulation. For example, in rat hippocampal cultures, chronic activity blockade by NMDA antagonists results in an increase in the number of NMDA receptor clusters (Rao and Craig, 1997). Furthermore, in cultured cerebellar granule cells, NMDA agonists induce a downregulation of NMDA receptors involving a reduction in NR1 protein and its mRNA (Resink et al., 1996). In agreement with this report in which NMDA receptor downregulation was reversed by stopping agonist treatment, we have also found that interruption of NMDA chronic treatment for $24 \mathrm{hr}$ or more leads to a recovery of both NR1 levels and the vulnerability of spinal cord to excitotoxicity. This would be in agreement with NMDA receptor turnover studies, which indicate that surface NR1 subunit has a half-life of $34 \mathrm{hr}$ (Huh and Wenthold, 1999). On the other hand, we observe that, to obtain the maximal trophic effects, the regimen of NMDA treatment must include an early injection on E5. At this age, immature MNs are normally resistant to excitotoxicity (Cal- 

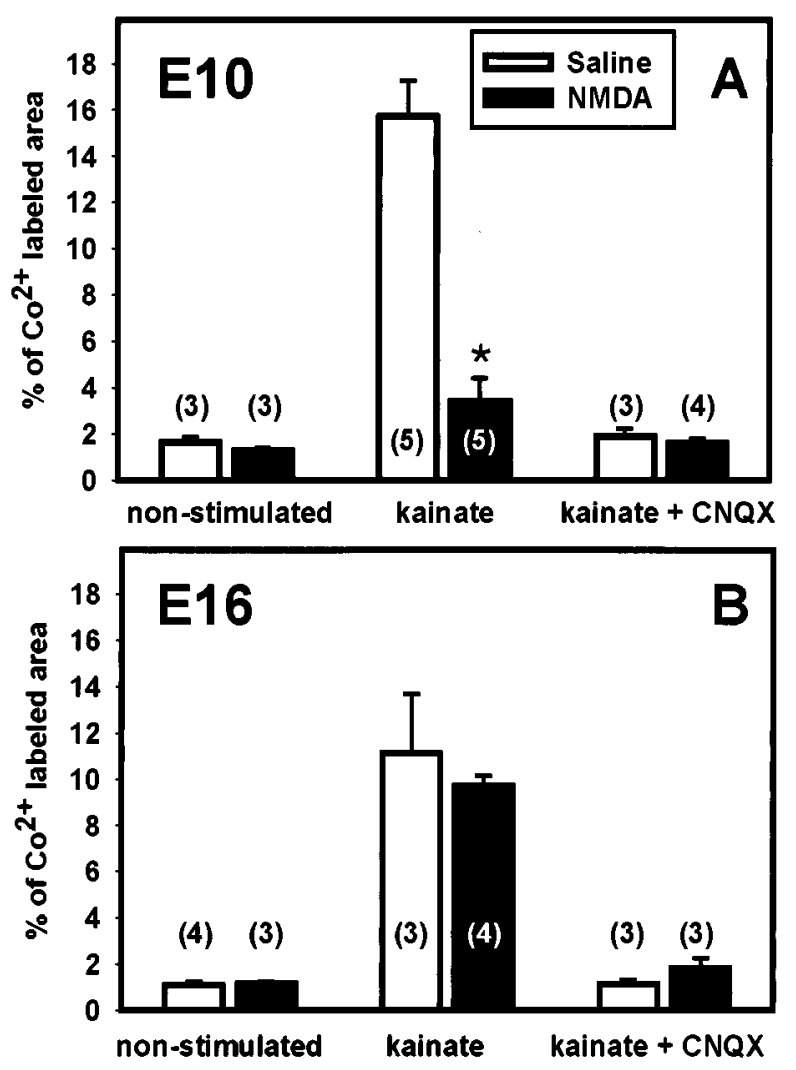

Figure 7. Morphometric evaluation of kainate-induced $\mathrm{Co}^{2+}$ uptake. Graphs show the percentage (mean \pm SEM) of the $\mathrm{Co}^{2+}$-labeled area in the LMC of spinal cord of E10 $(A)$ and E16 $(B)$ chick embryos treated with either saline or NMDA from E5 to E9. ${ }^{*} p<0.001$ versus saline (Student's $t$ test). Numbers in parentheses indicate sample sizes.

deró et al., 1997), although they express low levels of NMDA receptors (our unpublished observations). This suggests that activation of low levels of functional NMDA receptors are required to initiate the NMDA receptor agonist-induced trophic effects on MN survival.

Peripherally (muscle) derived signals are the main known regulators of $\mathrm{MN}$ survival between E6 and E12 in the chick embryo (Calderó et al., 1998b), whereas signals derived from afferent projections appear to operate primarily after E10 to maintain the survival of MNs (Okado and Oppenheim, 1984). Because trophic NMDA treatment rescues MNs from PCD before E10 and also prevents target deprivation-induced death, it seems likely that NMDA has a central effect through glutamate receptors present on MNs. Thus, the glutamate receptor downregulation observed in this situation would sustain agonistinduced calcium entry within the limits required for survival in the absence of peripheral trophic support. However, because after E10 glutamate receptor agonists are not able to promote $\mathrm{MN}$ survival, there must be a critical period in which the activation of NMDA receptors leads to a reduction of glutamate receptor function. In fact, there are reports that the sensitivity of NMDA receptors to pharmacological regulation changes during development (Scheetz and Constantine-Paton, 1994). The present data provide the first evidence that normal PCD of MNs is regulated, in part, by afferents via activation of NMDA receptors.

Neuromuscular activity during development is also an important signal for regulating MN survival and differentiation (Pitt- man and Oppenheim, 1978; Oppenheim and Núñez, 1982). We have shown here that NMDA trophic treatment causes a significant decrease in motility after E10, accompanied by muscular atrophy, but without a reduction in the number of MNs. This indicates that chronic NMDA treatment has a long-lasting effect on the ability of spinal cord circuitry to generate motor activity. It has been suggested that, during postnatal development in rat, activity blockade may increase the vulnerability of MNs to the putative toxic effects of excitatory afferent synaptic inputs (Fournier Le Ray et al., 1993; Greensmith and Vrbova, 1996). If correct, this may also help to explain the loss of rescued MNs that we observe after E10, owing to residual circulating NMDA or endogenous glutamate in our treatment paradigm.

We have observed that early pretreatment with NMDA protects against later exposure to excitotoxic doses of NMDA (see also Marini and Paul, 1992; Dickie et al., 1996). Interestingly, we have found that this NMDA-induced excitoprotection is not restricted to NMDA receptors but also affords protection against other non-NMDA receptor-acting excitotoxins, such as kainate or AMPA. Measures of $\mathrm{Co}^{2+}$ uptake induced by kainate demonstrate that, as a consequence of NMDA pretreatment, $\mathrm{Ca}^{2+}$ permeable AMPA-kainate receptors are functionally downregulated, similar to the NMDA receptor. Thus, it seems likely that both the excitoprotective and neurotrophic (inhibition of PCD) actions observed here are mainly linked to reductions in agonistinduced calcium loading as a consequence of receptor downregulation. It is known that treatment with different neurotransmitters or neurotransmitter agonists causes marked alterations in the localization of corresponding receptors (Mantyh et al., 1995; Liu et al., 1997; Dumartin et al., 1998). Although these findings have not yet been extended to glutamate receptors, it seems possible that chronic treatment with NMDA induces the internalization of both NMDA and non-NMDA receptors, thereby limiting receptor availability for extracellular ligands. In fact, there is some evidence that indicates that both AMPA and NMDA receptors are downregulated together by a mechanism involving subunit degradation after NMDA receptor activation (Huh and Wenthold, 1997). Alternatively, we cannot rule out the possibility that NMDA pretreatment may cause an upregulation of neuro-

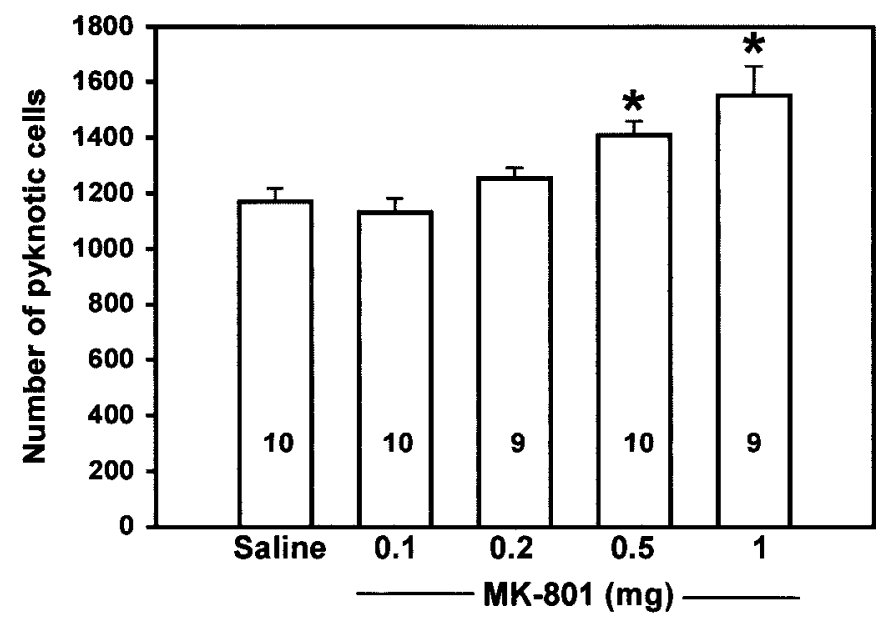

Figure 8. MK-801 increases motoneuron death during the period of normal PCD. Number (mean \pm SEM) of pyknotic cells in the lumbar LMC of chick embryos after treatment with either saline or different doses of MK-801 on E7. Counts were made $12 \mathrm{hr}$ after the treatment. Numbers in bars indicate the sample size. ${ }^{*} p<0.01$, Student's $t$ test. 
trophic factors-receptors (or other molecules), which may play an excitoprotective role (Hughes et al., 1993). For instance, the elevation of cAMP mimics the survival-promoting effects of depolarization or glutamate receptor activation by inducing high levels of cell surface neurotrophin TrkB receptors in cultured neurons (Meyer-Franke et al., 1998).

An important question that needs to be addressed is the physiological relevance of the present results in the context of activitymediated control of MN survival. Although our results involve pharmacological alteration of the system, we report here for the first time that NMDA receptor stimulation has a survivalpromoting influence on MNs in vivo, whereas acute receptor inactivation by MK-801 has the opposite effect. Recently, it has been reported that blockade of NMDA receptors triggers apoptotic neurodegeneration in developing rat brain, suggesting that glutamate acts as a physiological regulator of PCD (Ikonomidou et al., 1999). Further studies are needed to determine whether glutamate normally released by afferent inputs can regulate intracellular calcium in MNs and how glutamate cooperates with target-derived neurotrophic factors in regulating normal $\mathrm{MN}$ death and survival.

\section{REFERENCES}

Allcorn S, Catsicas M, Mobbs P (1996) Developmental expression and self-regulation of $\mathrm{Ca}^{2+}$ entry via AMPA/KA receptors in the embryonic chick retina. Eur J Neurosci 8:2499-2510.

Balázs R, Hack N, Jørgensen OS (1988) N-methyl-D-aspartate promotes the survival of cerebellar granule cells in culture. Neuroscience $27: 437-451$.

Barger SW, Mattson MP (1995) Excitatory amino acids and growth factors: biological and molecular interactions regulating neuronal survival and plasticity. In: CNS neurotransmitters and neuromodulators: glutamate (Stone TW, ed), pp 273-294. Boca Raton, FL: CRC.

Barry MA, O’Donovan MJ (1987) The effects of excitatory amino acids and their antagonists on the generation of motor activity in the isolated chick spinal cord. Dev Brain Res 36:271-276.

Burgoyne RD, Graham ME, Cambray-Deakin M (1993) Neurotrophic effects of NMDA receptor activation on developing cerebellar granule cells. J Neurocytol 22:689-695.

Caicedo A, Kungel M, Pujol R, Friauf E (1998) Glutamate-induced $\mathrm{Co}^{2+}$ uptake in rat auditory brainstem neurons reveals developmental changes in $\mathrm{Ca}^{2+}$ permeability of glutamate receptors. Eur J Neurosci 10:941-954.

Calderó J, Ciutat D, Lladó J, Castán E, Oppenheim RW, Esquerda JE (1997) Effects of excitatory amino acids on neuromuscular development in the chick embryo. J Comp Neurol 387:73-95.

Calderó J, Lladó J, Ribera J, Tarabal O, Ciutat D, Casanovas A, Ayala V, Casas C, Serrando M, Oppenheim RW, Esquerda JE (1998a) Prevention of normal and induced programmed cell death by chronic administration of $N$-methyl-D-aspartate (NMDA). Soc Neurosci Abstr 24:1790.

Calderó J, Prevette D, Mei X, Oakley RA, Li L, Milligan C, Houenou L, Burek M, Oppenheim RW (1998b) Peripheral target regulation of the development and survival of spinal sensory and motor neurons in the chick embryo. J Neurosci 18:356-370.

Choi DW (1987) Ionic dependence of glutamate neurotoxicity. J Neurosci 7:369-379.

Chu-Wang I-W, Oppenheim RW (1978) Cell death of motoneurons in the chick embryo spinal cord. I. A light and electron microscopic study of naturally occurring and induced cell loss during development. J Comp Neurol 177:33-58.

Ciutat D, Calderó J, Oppenheim RW, Esquerda JE (1996) Schwann cell apoptosis during normal development and after axonal degeneration induced by neurotoxins in the chick embryo. J Neurosci 16:3979-3990.

Clarke PGH, Oppenheim RW (1995) Neuron death in vertebrate development: in vivo methods. In: Methods in cell biology: cell death, Vol 46 (Schwartz LM, Osborne BA, eds), pp 277-321. New York: Academic.
deLapeyrière O, Henderson CE (1997) Motoneuron differentiation, survival and synaptogenesis. Curr Opin Genet Dev 7:642-650.

Dickie BGM, Holmes C, Greenfield SA (1996) Neurotoxic and neurotrophic effects of chronic $N$-methyl-D-aspartate exposure upon mesencephalic dopaminergic neurons in organotypic culture. Neuroscience 72:731-741.

Dumartin B, Caillé I, Gonon F, Bloch B (1998) Internalization of D1 dopamine receptor in striatal neurons in vivo as evidence of activation by dopamine agonists. J Neurosci 18:1650-1661.

Fournier Le Ray C, Prevette D, Oppenheim RW, Fontaine-Perus J (1993) Interactions between spinal cord stimulation and activity blockade in the regulation of synaptogenesis and motoneuron survival in the chick embryo. J Neurobiol 24:1142-1156.

Fryer HJL, Knox RJ, Strittmatter SM, Kalb RG (1999) Excitotoxic death of a subset of embryonic rat motor neurons in vitro. J Neurochem 72:500-513.

Gallo V, Kingsbury A, Balazs R, Jørgensen OS (1987) The role of depolarization in the diferentiation of cerebellar granule cells in culture. J Neurosci 7:2203-2213.

Greensmith L, Vrbova G (1996) Motoneuron survival: a functional approach. Trends Neurosci 19:450-455.

Hamburger V (1958) Regression versus peripheral control of differentiation in motor hypoplasia. Am J Anat 102:365-409.

Hamburger V (1975) Cell death in the development of the lateral motor column of the chick embryo. J Comp Neurol 160:535-546.

Hamburger V, Hamilton HL (1951) A series of normal stages in the development of the chick embryo. J Morphol 88:49-92.

Hughes P, Beilharz E, Gluckman P, Dragunow M (1993) Brain-derived neurotrophic factor is induced as immediate early gene following $N$-methyl-D-aspartate receptor activation. Neuroscience 57:319-328.

Huh KH, Wenthold RJ (1997) Turnover and regulation of ionotropic glutamate receptors in cultured cerebellar granule cells. Soc Neurosci Abstr 23:935.

Huh KH, Wenthold RJ (1999) Turnover analysis of glutamate receptors identifies a rapidly degraded pool of the $N$-methyl-D-aspartate receptor subunit, NR1, in cultured cerebellar granule cells. J Biol Chem 274:151-157.

Ikonomidou C, Bosch F, Miksa M, Bittigau P, Vockler J, Dikranian K, Tenkova TI, Stefovska V, Turski L, Olney JW (1999) Blockade of NMDA receptors and apoptotic neurodegeneration in the developing brain. Science 283:70-74.

Johnson Jr EM, Koike T, Franklin J (1992) A “calcium set-point" hypothesis of neuronal dependence on neurotrophic factor. Exp Neurol 115:163-166.

Koike T, Martin DP, Johnson Jr EM (1989) Role of calcium channels in the ability of membrane depolarization to prevent normal death induced by trophic deprivation: evidence that levels of internal $\mathrm{Ca}^{2+}$ determine nerve growth factor dependence of sympathetic ganglion cells. Proc Natl Acad Sci USA 86:6421-6425.

Liu H, Mantyh PW, Basbaum AI (1997) NMDA-receptor regulation of substance $\mathrm{P}$ release from primary afferent nociceptors. Nature 386:721-724.

Mantyh PW, Allen CJ, Ghilardi JR, Rogers SD, Mantyh CR, Liu H, Basbaum AI, Vigna SR, Maggio JE (1995) Rapid endocytosis of a G-protein-coupled receptor: substance P-evoked internalization of its receptor in the rat striatum in vivo. Proc Natl Acad Sci USA 92:2622-2626.

Marini AM, Paul SM (1992) N-methyl-D-aspartate receptor-mediated neuroprotection in cerebellar granule cells requires new RNA and protein synthesis. Proc Natl Acad Sci USA 89:6555-6559.

Meyer-Franke A, Wilkinson GA, Kruttgen A, Hu M, Munro E, Hanson Jr MG, Reichard LF, Barres BB (1998) Depolarization and cAMP elevation rapidly recruit TrkB to the plasma membrane of CNS neurons. Neuron 21:681-693.

Nishi R, Berg DK (1981) Effects of high $\mathrm{K}^{+}$concentrations on the growth and development of ciliary ganglion neurons in cell culture. Dev Biol 87:301-307.

Okado N, Oppenheim RW (1984) Cell death of motoneurons in the chick embryo spinal cord. IX. The loss of motoneurons following removal of afferent inputs. J Neurosci 4:1639-1652.

Oppenheim RW (1991) Cell death during the development of the nervous system. Annu Rev Neurosci 14:453-501.

Oppenheim RW, Núñez R (1982) Electrical stimulation of hindlimb increases neuronal cell death in chick embryo. Nature 295:57-59.

Oppenheim RW, Chu-Wang I-W, Maderdrut JL (1978) Cell death of 
motoneurons in the chick embryo spinal cord. III. The differentiation of motoneurons prior to their induced degeneration following limb-bud removal. J Comp Neurol 177:87-112.

Pittman RH, Oppenheim RW (1978) Neuromuscular blockade increases motoneuron survival during normal cell death in the chick embryo. Nature 271:364-365.

Pruss RM, Akeson RL, Racke MM, Wilburn JL (1991) Agonistactivated cobalt uptake identifies divalent cation-permeable kainate receptors on neurons and glial cells. Neuron 7:509-518.

Rao A, Craig AM (1997) Activity regulates the synaptic localization of the NMDA receptor in hippocampal neurons. Neuron 19:801-812.

Resink A, Villa M, Benke D, Hidaka H, Möhler H, Balázs R (1996)
Characterization of agonist-induced down-regulation of NMDA receptors in cerebellar granule cell cultures. J Neurochem 66:369-377.

Scheetz AJ, Constantine-Paton M (1994) Modulation of NMDA receptor function: implications for vertebrate neural development. FASEB J 8:745-752.

Soler RM, Egea J, Mintenig GM, Sanz-Rodriguez C, Iglesias M, Comella JX (1998) Calmodulin is involved in membrane depolarizationmediated survival of motoneurons by phosphatidylinositol-3-kinaseand MAPK-independent mechanisms. J Neurosci 18:1230-1239.

Zhang FX, Rubin R, Rooney TA (1998) N-methyl-D-aspartate inhibits apoptosis through activation of phosphatidylinositol 3-kinase in cerebellar granule neurons. J Biol Chem 273:26596-26602. 